\title{
Aluminium sucrose biscuit fillings to control hyperphosphataemia in patients undergoing dialysis
}

\author{
ROGER GABRIEL，JUNE MORGAN
}

\begin{abstract}
Aluminium hydroxide is used to prevent hyperphosphataemia in patients undergoing dialysis, but many standard preparations are unpalatable. In this study hydrated aluminium sucrose was suspended in synthetic cream and used as a biscuit filling. Six patients undergoing dialysis took part in five five-week study periods comparing different forms of treatment. No significant difference was found between serum phosphate concentrations measured during standard treatment and those measured during treatment with aluminium sucrose biscuits. There was no significant difference in serum phosphate concentrations when the patients were given placebo biscuits and when they received no treatment.

Aluminium sucrose presented in this form was an adequate phosphate binder and was acceptable to the patients.
\end{abstract}

\section{Introduction}

Aluminium hydroxide is widely used in most renal units to prevent hyperphosphataemia between dialyses and hence the possibility of metastatic calcification. There are drawbacks to the preparations available: the liquid form is unpalatable, the tablet form tends to dry the mouth and gullet, and some patients find

\author{
Patients, methods, and results
}

Six patients undergoing haemodialysis in hospital (three men, three women) with a mean age of 47.5 years agreed to participate in the $\frac{C}{\sigma}$ study, which had been approved by the St Mary's Hospital ethical $\overline{\bar{m}}$ committee. Each biscuit contained $2 \mathrm{~g}$ aluminium sucrose powder, the $\vec{\nabla}$ dose being adjusted so that three biscuits contained the equivalent $\cong$ quantity of aluminium hydroxide present in four Alu-caps (1900 mg). \& The patients underwent five study periods, each lasting five weeks. $\vec{\nabla}$ In the first study period the patients were treated with Alu-caps, in the second period they had no treatment, in the third they were $\overrightarrow{\vec{\omega}}$ treated with aluminium sucrose biscuits, in the fourth with placebo $\mathscr{\sigma}$ biscuits containing no aluminium sucrose, and in the fifth with Alu-caps.

Three $\mathrm{ml}$ of blood was taken for estimation of serum phosphate concentration immediately before each twice-weekly dialysis. In three $\stackrel{\infty}{\omega}$ patients undergoing dialysis in the late afternoon, serum was separated before assay the following day. Each patient was dialysed using a $\infty_{\infty}^{\infty}$ hollow-fibre dialyser for six to seven hours twice weekly. No change is in dialysis schedule or diet (which contained $5-600 \mathrm{mg}$ phosphate daily) was made during the 25 weeks of the study. Blood flow was kept $\infty$ as constant as possible using two Avon needles of the same size in each patient for each dialysis; dialysate flow was constant at $500 \mathrm{~N}$ ml minute.

Serum phosphate concentrations estimated during treatment with Alu-caps were not significantly different from those estimated during $\vec{\bullet}$ treatment with aluminium sucrose biscuits. Similarly, there was no $\infty$ significant difference between serum phosphate concentrations. estimated during the period without treatment and those estimated when patients were taking placebo biscuits (see table).

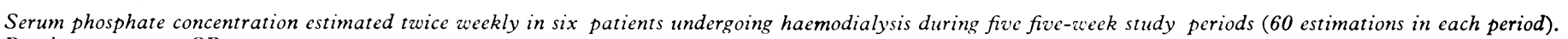
Results are mean $\pm S D$

\begin{tabular}{|c|c|c|c|c|c|}
\hline & $\begin{array}{c}\text { Alu-caps } \\
\text { (two twice a day) }\end{array}$ & No treatment & $\begin{array}{c}\text { Aluminium sucrose biscuits } \\
\text { (three times a day) }\end{array}$ & $\begin{array}{l}\text { Placebo biscuits } \\
\text { (three times a day) }\end{array}$ & $\begin{array}{c}\text { Alu-caps } \\
\text { (two twice a day) }\end{array}$ \\
\hline Serum phosphate $(\mathrm{mmol} / \mathrm{l})$ & $1 \cdot 31 \div 0.31$ & $2 \cdot 04: 0.34$ & $1.32: 0.13$ & $1.96 \div 0.55$ & $1 \cdot 25 \pm 0.38$ \\
\hline
\end{tabular}

Conversion: SI to traditional units-Phosphate: $1 \mathrm{mmol} / 1=3.1 \mathrm{mg} 100 \mathrm{ml}$.

the capsule form difficult to swallow. To avoid these difficulties we have used hydrated aluminium sucrose suspended in synthetic cream presented to the patient as a custard-creamfilled biscuit sandwich. Aluminium hydroxide gel cookies are baked in some American renal units, ${ }^{1}$ but their efficacy as a phosphate binder has not been compared with standard preparations.

\section{Discussion}

It is clear that the aluminium sucrose presented in this form 응 acted as an adequate phosphate binder in the gut. All patients $N$ preferred the biscuit presentation of aluminium sucrose to conventional aluminium hydroxide preparations. They were unable to taste the aluminium sucrose in synthetic cream.

We wish to thank Welfare Foods (Stockport) Ltd for supplying the biscuits used in this study.

\section{Reference}

1 Johnson K. Review of amphojel cookies and kayexalate candy. Dialysis and Transplantation 1979;8:145.

(Accepted 23 fune 1981)
London W2 1NY

ROGER GABRIEL, BA, FRCP, renal physician

JUNE MORGAN, SRD, senior dietitian 